\title{
Mobile-Based Fuzzy Expert System for Diagnosing Malaria (MFES)
}

\author{
Alaba T. Owoseni \\ Department of Computer Science, Interlink Polytechnic, Ijebu Jesa, Nigeria \\ E-mail: atimothyowoseni@yahoo.com \\ Isaac O. Ogundahunsi \\ Department of Computer Science, Interlink Polytechnic, Ijebu Jesa, Nigeria \\ E-mail: jideogundahunsi@yahoo.com
}

\begin{abstract}
Malaria is a deadly disease that claims yearly lives of millions in Africa, and other endemic continents. The prevalence of malaria in these endemic regions is majorly attached to the lack of competent medical experts who are capable of providing medical care for the affected victims. This study considers developing a mobile based fuzzy expert system that could assist in diagnosing malaria. The fuzzification of crisp inputs by the system was carried out using an inter-valued and triangular membership functions while the deffuzification of the inference engine outputs was performed by weighted average method. Root sum square method of drawing inferences has been employed while the whole development has been achieved with the help of Java 2 Micro Edition of Java. This expert system executes on the readily available mobile devices of the patients. This fuzzy system was finally evaluated and confirmed effective in providing a human-expert like diagnosis.
\end{abstract}

Index Terms - Mobile Fuzzy System, Malaria Diagnosis, Expert System, Interval-valued Fuzzy Set, Triangular Membership Function, Membership Function.

\section{INTRODUCTION}

Malaria is a deadly disease that is prevalent in Africa and some other parts of the globe (Asia, Central and South America). Estimate shows that more than 3 billion people are at the risk of been infected by this disease and these people settle across 99 countries in the world while, millions of them die annually of this disease. History also reviews that this disease has been around since ancient times but there was no any success in discovering the cause of the disease until 1880 when Alphonse Laveran discovered the single-celled parasite called plasmodium as the cause of the disease [1]. Some years later, anopheles mosquitoes were discovered as the carriers of this disease and that the parasite is also capable of living partly in man as the secondary host.

There are over a hundred species of plasmodium in existence but four of these species commonly infect human beings [1]. These common species are: plasmodium falciparum- that is seen as the major cause of death in Africa, mostly spread after plasmodium vivax and most deadly; plasmodium vivax- the most widely spread specie and it causes symptoms that are of mild severity in man; plasmodium malariae- it is capable of persisting in the blood for very long period of time, possibly decades, without even producing symptoms and finally, the most popular specie in west Africa, plasmodium ovale.

Since the cause of malaria has been discovered, all efforts have been made by organizations, governments and individuals to ensure that this deadly disease is eradicated. Some of these efforts most especially by the World Health Organization include: distribution of treated nets, anti-malaria drugs, window screens, insect repellents and enlightenment to people that reside in malaria prone countries. However, the rate at which malaria prevails in the concerned areas seems exponential despite the fact that all hands are on desk to combat the spread and even eradicate the disease.

There are various reasons for the usual growth in the disease most especially in West Africa. Some of these reasons include: ignorance, environmental factors and the low percentage of medical practitioners who are keen at diagnosing and providing medical care to patients of this disease. The lastly mentioned reason is seen as the main cause for the high degree of malaria prevalence in West Africa. To tackle this issue of insufficient medical practitioners, many researchers have attempted the application of advancements in Information Technology to equalizing the ratio of patients to medical practitioners by developing expert systems that can personify the human experts in the field of diagnosis and therapy of malaria. With all these available medical expert systems, there is still an unquenched need in helping the equalization of the ratio most especially with the increase in the population of Africans and more so, the weaknesses in strength (accessibility, reasoning, cost, usability, codified expert knowledge) of some of these systems in addressing the issue as expected.

Medical diagnosis is a process of identifying an illness or problem by the examination of the symptoms believed to have shown due to the presence of the illness. The general symptoms that are associated with malaria are: fever, sweating, high body temperature, chills, headache, 
malaise, fatigue, muscular pains, nausea, vomiting, and diarrhea [1]. While Therapy, is a treatment for a physical or mental disorder. In medicine, both diagnosis and therapy are activities that require high level of expertise to handle and in lieu of this, medical experts are only allowed to carry out the two medical activities.

This research develops a mobile based fuzzy expert system (MFES) that is effective in carrying out a diagnosis of malaria in a manner that is expected of an expert in the area of malaria diagnosis and also objected at helping to equalize the ratio of patients to medical practitioners. It is capable of providing a human like approach of diagnosing with vagueness as inherent in medical diagnosis and not like the crisp like approach of diagnosing with exactness as considered by some past researches. This Mamdani fuzzy system consists of four main components as illustrated in fig.3.1 and is capable of been executed on mobile devices. The mobile devices on which this fuzzy system executes are technically targeted at due to a survey that showed the likelihood of every African between the ages of 7-90years using one of these forms of mobile device (usually mobile cell phone) that is capable of executing the developed fuzzy system. This chosen hardware platform for this expert system makes it readily available to patients at absolutely no cost (no need for extra technical knowhow, network connectivity, etc.) hence, achieving one of its goals that is, general accessibility.

\section{REVIEW OF RELATED WORK}

There have been many research works carried out on the application of Information Technology to Medical care. These research works can be classified into medical information management, telemedicine under which $\mathrm{m}$ health and e-health reside and also expert system. In this section of the research, review of expert system related works will be considered.

Considered in [2] was the development of a rule based expert system for diagnosing fever. The web based expert system used Visual Basic Dot Net (VB .Net) as the language of its implementation while the rules within the knowledge base were Boolean rules and not fuzzy rules hence; drawing of inference as performed by this system could not have a high degree of human like way of reasoning.

Also in [3], a web based diagnosis and therapy system that used a machine learning technique was developed. According to the study, a machine learning technique rough set was used on labeled sets of malaria fever symptoms collected to generate explainable rules for each level of severity. The developed system labeled database, was divided into five cases of malaria and the classification accuracy on training dataset was described to be $100 \%$ while that of testing data set was $94 \%$. Even though the study claimed to have developed a web based diagnosis and therapy system that could be accessed anywhere and anytime, it should not escape the minds of individuals that not all the intended users of the system could have used it due to the fact that the majority of the users might be illiterate of the use of the internet and also the cost attached to accessing the developed system since it was web based.

Proposed in [3] was a framework to construct a fuzzy expert system that would diagnose viral infection for mobile users. The proposed system was expected to be hosted on the web server and web service of it would be used as a communication medium between the mobile devices and the expert system. However, it was just a proposal and there was no any attempt in executing the proposed work. More so, an actualization of the proposed system will still need connection of the mobile users with internet for its accessibility. This need for internet connection will eventually render the actualized form of the system into a partially used system.

A work on fuzzy expert system for the management of malaria (FESM) was executed in [4]. The concerned system was described as capable of providing decision support platform to malaria researchers, medical doctors and other healthcare practitioners in malaria endemic regions. This developed System was composed of Knowledge Base, the Fuzzifier, the Inference Engine and Defuzzifier. The developed system used a triangular typed membership function for the fuzzification of scalar inputs, a fuzzy inference method of root sum square (RSS) and finally, the defuzzifier employed the popular and effective center of gravity method of defuzzification. Although, in the study 35 selected patients of malaria were diagnosed with the system but, there were no snapshots of the system's interfaces included in the work and the type (mobile standalone or web-based) of system developed was not vividly stated and clarified, for it might be referred to as an ordinary mathematical model that might need to be implemented using any programming language.

In [5], a medical decision support system that was capable of diagnosing malaria using analytic hierarchy process was developed. This system that used Knowledge components: chemotherapy, patient characteristics, patient information, patient examination, symptom intensity and medical history, was able to determine the priority order of basic malaria diagnosis criteria. However, this developed decision support system was not considered as a mobile based software system that could be targeted at every of the concerned patients.

Considered in [6] was the development of a clinical protocol-based decision support system (PBDSS) for the treatment of malaria. This system was able to provide a treatment based on the level of severity of the disease.

Moreover, in [7] a standalone expert system that could be used as a prompt diagnostic tool was developed. It combined the action-oriented integrated management of child illnesses (IMCI) and the disease-oriented health information systems (HIS) approaches to diagnose malaria and typhoid fever in the rural areas of the Nigerdelta region of Nigeria. However, the developed system as a standalone application has restricted its accessibility and also, it carried out its reasoning on certainties and not like the fuzzy systems. 
Also, in [8], work on the development of a medical diagnostic expert system using structured system analysis and design method (SSADM) was considered. This developed system was found to be effective in assisting both young and old medical practitioners in making professional medical diagnosis. However, the developed system was not a mobile system for it used Turbo Prolog as the programming language in its development.

According [9], it was estimated the impact of hypothetical new diagnostics that could replace clinical judgment. In this work, a decision tree model was introduced in detecting plasmodium faciparum malaria in febrile children at an early age less than five years.

In [10] as reviewed by [3], there was a consideration of the diagnosis and therapy of uncomplicated and severe malaria caused by all the species of plasmodium in special groups of patients: children, pregnant women and HIV/AIDS patients who are travelers from malaria and non-malaria endemic regions.

In [11], Chandramohan et al., (2001) developed and evaluated a clinical algorithm. This development of the algorithm came up after a study on 1945 children and 2885 adults who suffered from fever in a hospital outpatients clinic in India. It was finally concluded at the end of the evaluation that malaria diagnosis in area of low endemicity requires microscopy to be accurate.

An algorithm which could be used by fieldworkers and that also had a similar sensitivity and specificity for the diagnosis of malaria as that of an expert in pediatric was researched at in [12]. The developed algorithm was considered to have been validated prospectively on 518 children who were presented to the Medical Research Council Clinic located at Basse, Gambia.

Review of the above literatures showed that some grouped works on the development of expert system for malaria diagnosis and therapy have considered its execution on standalone systems or the internet (a network of computer system networks). These works that are in this group could not be freely accessed by patients that were at the developing parts of endemic countries due to the cost of connecting to the internet, buying computer systems and also the need for technical knowhow. Hence the ideology of an application being standalone or web based and that it is accessible anywhere anytime only applies to some and not all.

However, current literatures on mobile expert system are either proposals, systems considering diagnosis of other ailments or works that have considered a non-fuzzy form of inference available medical knowledge just as we have in [13] and [14].

\section{RESEARCH METHODOLOGY}

This section of the paper describes the hardware and software tools that form the materials used in the study and also the methods employed as properly considered below:

\section{A. Materials}

The development of MFES has employed the use of some hardware and software tools. The hardware tools are: a Compaq Mini Computer System and X2 Nokia Cell Phone. The software tools include: ClamshellCldcPhone1 Emulator, Netbeans 7.0.1 as the IDE (Integrated Development Environment), JDK 1.6 and Windows 7 Ultimate Operating System.

\section{B. Methods}

The method of Human-Computer interaction used by the system is that of Graphic User Interface that makes use of graphic elements. The transformation of scalar inputs into fuzzy inputs in the study has employed both interval-valued membership function as shown in fig. 3.2 while the knowledge represented in the knowledge base are in the form of fuzzy rules using the generalized modus ponens. The drawing of inferences from the fuzzy rules uses root sum square method and the defuzzication of inference engine outputs by the developed system makes use of weighted average.

\section{MFES Architecture}

MFES has five main components: User Interface, Fuzzifier, Knowledge Base, Inference Engine and Defuzzifier as shown in fig. 1. Each of these is discussed below:

\section{1) User Interface}

This is the medium through which the patient(s) interact with the system. Reports of diagnosis are conveyed back to the users through this medium as well. It employs the use of GUI (Graphic User Interface) Human-Computer Interaction technique in its design. This technique uses graphic components such as radio buttons (choice elements in J2ME), static textboxes (String Items in J2ME), command buttons, message boxes, and images. Each of these components responses to users' action (events) through checks, clicks, selections and so on. This approach has some advantages over its predecessors (command prompt and menu).

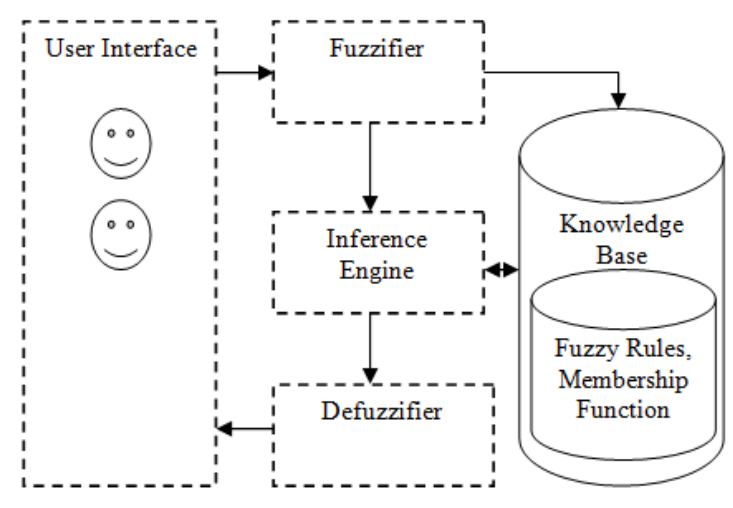

Fig.1. MFES Architectural Design

\section{2) Fuzzifier}

Fuzzification is the process of transforming a crisp quantity into a fuzzy quantity or the process of transforming real scalar values into fuzzy values. There are different forms of membership functions (fuzzifiers) 
that can be used for the fuzzification of scalar quantity. These include: bell-shaped ( $\pi$-curve), S-shaped (S-curve), a reverse S-curve (Z-curve), and Gaussian, Triangular, and Trapezoidal fuzzifiers [15].

There are eleven symptoms considered associated with malaria in this research according to the interviewed medical experts and other generally accepted literatures in the field of medicine. These symptoms: fever, sweating, high body temperature, chills, headache, malaise, fatigue, muscular pains, nausea, vomiting, and diarrhea [1], are medically believed to be the symptoms associated with malaria. However, there may be some other symptoms known to be specific to some other patients (pregnant women). In this research, each symptom is seen as a universe of discourse that contains patients who show it and from this universe of discourse; interval-valued fuzzy sets are obtained. Each fuzzy set is described by an interval-valued membership function such as the one shown in fig. 2. In this figure, for a particular element, $\mathrm{k}=\mathrm{p}$, its grade of membership in a fuzzy set $\mathrm{A}$ i.e. $\mu \mathrm{A}(\mathrm{p})$ would be expressed by the membership interval $[\alpha 1, \alpha 2]$.

For instance, considering symptom headache as a universe of discourse that contains patients who show it and from which an interval-valued fuzzy set (A) is extracted, this is described as follows and represented in fig. 3:

$\mathrm{A}=\{($ mild, $0.1 \leqslant \mu \mathrm{A}$ (mild) $<0.3)$, (moderate, $0.3 \leqslant$ $\mu \mathrm{A}($ moderate $)<0.6)$ (severe, $0.6 \leqslant \mu \mathrm{A}$ (severe) $<0.8$ ), (very severe, $0.8 \leqslant \mu \mathrm{A}$ (very severe) $\leqslant 1.0)\}$

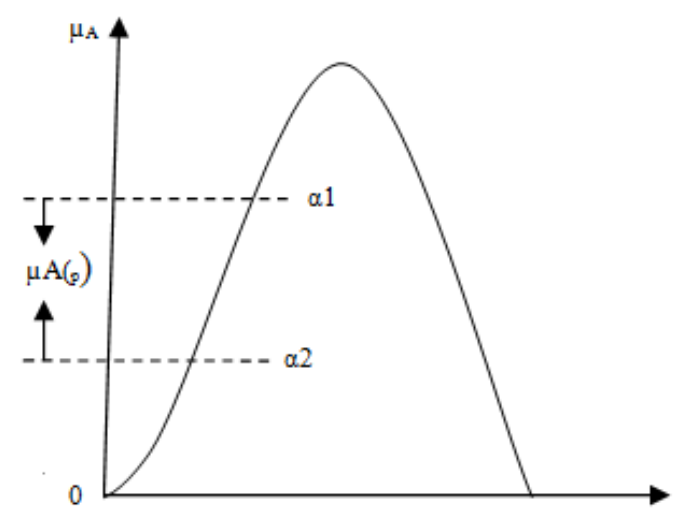

Fig.2. Interval-Valued Membership Function

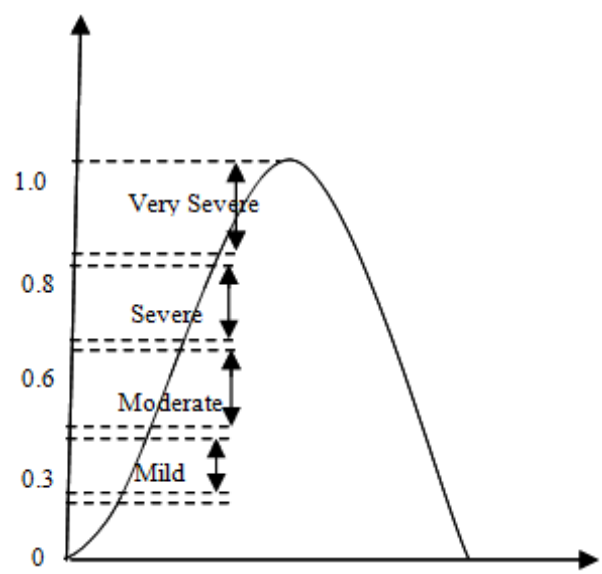

Fig.3. Interval-Valued Membership Function for Headache
These fuzzy values were the knowledge of the consulted medical experts. This interval-valued fuzzy set (A) and other symptoms were generalized further by allowing their intervals to become fuzzy. Therefore, each membership interval becomes an ordinary fuzzy set and triangular membership functions were used as shown in fig. 4.

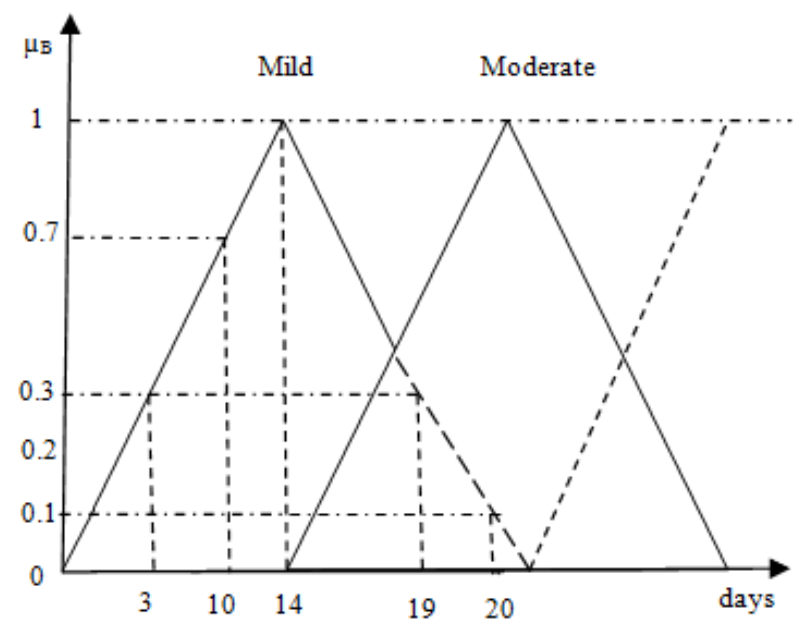

Fig.4. Triangular Membership Functions for the Fuzzy Set B

Given a fuzzy set (B) that stands as an ordinary fuzzy set for the membership interval (mild) in set (A), the ordinary fuzzy set (B) is denoted as:

$\mathrm{B}=\{(1,0.1),(2,0.1),(3,0.2),(4,0.3),(5,0.4),(6,0.4)$, $(7,0.5),(8,0.6),(9,0.6),(10,0.7),(11,0.8),(12,0.9)$, $(13,0.9),(14,1.0),(15,0.9),(16,0.7),(17,0.6),(18,0.5)$, $(19,0.3),(20,0.1)\}$

Also a fuzzy set (C) that stands as an ordinary fuzzy set for the membership interval (moderate) in set $(\mathrm{A})$ is denoted as:

$\mathrm{C}=\{(15,0.1),(16,0.3),(17,0.4),(18,0.6),(19,0.7)$, $(20,0.9),(21,1.0),(22,0.9),(23,0.7),(24,0.6),(25,0.4)$, $(26,0.3),(27,0.1)\}$

Fuzzy set (D) stands as an ordinary fuzzy set for the membership interval (severe) in set (A) is denoted as:

$\mathrm{D}=\{(22,0.1),(23,0.3),(24,0.4),(25,0.6),(26,0.7)$, $(27,0.9),(28,1.0),(29,0.9),(30,0.7),(31,0.6),(32,0.4)$, $(33,0.3),(34,0.1)\}$

Fuzzy set (E) as an ordinary set for the membership interval (very severe) in set (A) is:

$\mathrm{E}=\{(29,0.1),(30,0.3),(31,0.4),(32,0.6),(33,0.7)$, $(34,0.9),(35,1.0),(36,1.0),(37,1.0),(38,1.0),(39,1.0)$, $(40,1.0),(41,1.0) \ldots\}$

From the above fuzzy sets representation, each set consists of elements with each made up of the age of the symptom in days and the degree of its membership in the fuzzy set. 


\section{3) Knowledge Base}

Generally, this is the component that contains the extracted human expert knowledge in a computer understandable form. In this research, the knowledge that is represented in this component is gotten from four different medical experts who are good at providing medical diagnosis for malaria in a malaria endemic environment. This component is made up of two sub components: Rule base and Database.

Premise: if ( $x$ is $D)$ then ( $y$ is $E$ )

\begin{tabular}{|c|c|c|c|c|c|c|c|c|c|c|c|c|}
\hline Rule No & $\mathrm{Bt}$ & $\mathrm{Ch}$ & $\mathrm{Fa}$ & $\mathrm{Fe}$ & $\mathrm{Ha}$ & $\mathrm{Di}$ & $\mathrm{Ma}$ & $\mathrm{Mp}$ & $\mathrm{Na}$ & Sw & Vo & Conclusion \\
\hline 1 & $\operatorname{Mi}(0.1)$ & $\mathrm{Mi}(0.1)$ & $\mathrm{Mi}(0.1)$ & $\mathrm{Mi}(0.1)$ & $\mathrm{Mi}(0.1)$ & $\operatorname{Mi}(0.1)$ & $\operatorname{Mi}(0.1)$ & $\mathrm{Mi}(0.1)$ & $\mathrm{Mi}(0.1)$ & $\operatorname{Mi}(0.3)$ & $\operatorname{Mi}(0.1)$ & $\operatorname{Mi}(0.1)$ \\
\hline 2 & $\operatorname{Mi}(0.2)$ & $\mathrm{Mo}(0.2)$ & $\mathrm{Mo}(0.3)$ & $\mathrm{Mi}(0.4)$ & $\mathrm{Mo}(0.2)$ & $\mathrm{Mi}(0.2)$ & $\mathrm{Mo}(0.2)$ & $\operatorname{Mi}(0.3)$ & $\mathrm{Mi}(0.2)$ & $\operatorname{Mi}(0.3)$ & $\mathrm{Mo}(0.4)$ & $\operatorname{Mi}(0.2)$ \\
\hline 3 & $\mathrm{Se}(0.3)$ & $\operatorname{Mi}(0.5)$ & $\mathrm{Se}(0.3)$ & $\mathrm{Se}(0.3)$ & $\operatorname{Mi}(0.4)$ & $\mathrm{Mo}(0.6)$ & $\mathrm{Se}(0.3)$ & $\mathrm{Mi}(0.4)$ & $\mathrm{Mi}(0.4)$ & $\mathrm{Mi}(0.4)$ & $\operatorname{Mi}(0.3)$ & $\mathrm{Mo}(0.3)$ \\
\hline 4 & $\mathrm{Se}(0.3)$ & $\mathrm{Mo}(0.2)$ & $\mathrm{Mo}(0.2)$ & $\mathrm{Se}(0.3)$ & $\mathrm{Mi}(0.1)$ & $\mathrm{Mi}(0.1)$ & $\operatorname{Mi}(0.1)$ & $\mathrm{Mi}(0.1)$ & $\mathrm{Mo}(0.1)$ & $\operatorname{Mi}(0.1)$ & $\operatorname{Mi}(0.1)$ & $\operatorname{Mi}(0.1)$ \\
\hline 5 & $\operatorname{Mi}(0.7)$ & $\mathrm{Se}(0.3)$ & $\operatorname{Se}(0.3)$ & $\mathrm{Mo}(0.2)$ & $\operatorname{Mi}(0.6)$ & $\operatorname{Mi}(0.7)$ & $\mathrm{Mo}(0.5)$ & $\mathrm{Mo}(0.5)$ & $\mathrm{Mo}(0.4)$ & $\operatorname{Mi}(1.0)$ & $\mathrm{Mi}(1.0)$ & $\mathrm{Mi}(0.4)$ \\
\hline 6 & $\operatorname{Mi}(1.0)$ & $\mathrm{Se}(0.3)$ & $\operatorname{Mi}(0.5)$ & $\mathrm{Mi}(0.7)$ & $\mathrm{Se}(0.3)$ & $\operatorname{Mi}(0.8)$ & $\mathrm{Se}(0.3)$ & $\mathrm{Se}(0.3)$ & $\mathrm{Mi}(1.0)$ & $\mathrm{Se}(0.3)$ & $\mathrm{Mo}(0.2)$ & $\mathrm{Mo}(0.3)$ \\
\hline 7 & $\operatorname{Mi}(1.0)$ & $\mathrm{Se}(0.3)$ & $\mathrm{Se}(0.3)$ & $\mathrm{Mi}(0.3)$ & $\mathrm{Mo}(0.4)$ & $\mathrm{Se}(0.3)$ & $\mathrm{Mo}(0.3)$ & $M i(1.0)$ & $\mathrm{Se}(0.3)$ & $\operatorname{Mi}(1.0)$ & $\mathrm{Se}(0.3)$ & $\mathrm{Mo}(0.3)$ \\
\hline 8 & - & & - & - & - & - & $\mathrm{Mi}(0.2)$ & & - & & & $\operatorname{Mi}(0.2)$ \\
\hline 9 & & $\operatorname{Se}(0.7)$ & $\operatorname{Vs}(0.3)$ & $\mathrm{Mo}(0.8)$ & $\mathrm{Mo}(0.4)$ & $\operatorname{Se}(0.3)$ & Vs $(0.3)$ & $\operatorname{Vs}(0.3)$ & Vs(0.3) & $\operatorname{Se}(0.3)$ & & $\operatorname{Vs}(0.3)$ \\
\hline 10 & -1 & $\operatorname{Mi}(0.3)$ & - & $\mathrm{Mi}(0.3)$ & $\mathrm{Mi}(0.3)$ & $\mathrm{Mo}(0.2)$ & $\mathrm{Mo}(0.2)$ & $\operatorname{Mi}(0.3)$ & $\mathrm{Mo}(0.2)$ & & $\operatorname{Mi}(0.3)$ & $\operatorname{Mi}(0.2)$ \\
\hline 11 & $\operatorname{Mi}(0.2)$ & $\operatorname{Mi}(0.2)$ & - & $\mathrm{Mi}(0.2)$ & $\operatorname{Mi}(0.2)$ & $\operatorname{Mi}(0.2)$ & $\mathrm{Mi}(0.2)$ & $\operatorname{Mi}(0.2)$ & $\mathrm{Mi}(0.2)$ & $\operatorname{Mi}(0.2)$ & $\operatorname{Mi}(0.2)$ & $\operatorname{Mi}(0.2)$ \\
\hline 12 & $\operatorname{Mi}(0.2)$ & $\operatorname{Mo}(0.2)$ & $\mathrm{Mi}(0.2)$ & $\mathrm{Mi}(0.2)$ & $\mathrm{Mo}(0.2)$ & $\operatorname{Mi}(0.1)$ & $\mathrm{Mi}(0.2)$ & $\mathrm{Mi}(0.2)$ & $\mathrm{Mo}(0.2)$ & $\operatorname{Mi}(0.2)$ & $\operatorname{Mi}(0.2)$ & $\operatorname{Mi}(0.1)$ \\
\hline 13 & & $\mathrm{Mo}(0.8)$ & $\mathrm{Mo}(1.0)$ & $\operatorname{Mi}(0.8)$ & $\mathrm{Mo}(0.8)$ & $\mathrm{Mo}(1.0)$ & $\mathrm{Mo}(1.0)$ & $\mathrm{Se}(0.3)$ & $\mathrm{Se}(0.3)$ & $\mathrm{Mo}(1.0)$ & $\operatorname{Mi}(1.0)$ & $\mathrm{Se}(0.3)$ \\
\hline 14 & $\operatorname{Mi}(1.0)$ & $\mathrm{Mi}(1.0)$ & $\mathrm{Mi}(0.1)$ & $\operatorname{Vs}(0.3)$ & $\mathrm{Se}(0.8)$ & $\operatorname{Mi}(1.0)$ & & $\operatorname{Vs}(0.3)$ & - & $\mathrm{Vs}(0.3)$ & & Vs $(0.3)$ \\
\hline 15 & & & $\operatorname{Mi}(1.0)$ & - & - & & & & - & $\mathrm{Mo}(1.0)$ & & $\operatorname{Se}(0.3)$ \\
\hline 16 & $\mathrm{Mi}(1.0)$ & $\operatorname{Mi}(1.0)$ & Vs $(0.3)$ & $\mathrm{Mi}(1.0)$ & $\mathrm{Vs}(0.3)$ & $\mathrm{Se}(0.8)$ & $\operatorname{Mi}(1.0)$ & $\mathrm{Se}(0.8)$ & $\mathrm{Se}(0.8)$ & $\operatorname{Mi}(1.0)$ & & $\mathrm{Se}(0.3)$ \\
\hline 17 & -1 & - & $\operatorname{Vs}(0.3)$ & $\operatorname{Vs}(0.3)$ & $\mathrm{Se}(0.8)$ & & $\mathrm{Mo}(1.0)$ & - & $\mathrm{Se}(0.8)$ & & $\operatorname{Mo}(1.0)$ & Vs $(0.3)$ \\
\hline 18 & & 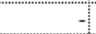 & & - & & : & $\mathrm{Se}(0.3)$ & $\mathrm{Se}(0.3)$ & $\mathrm{Mi}(0.1)$ & & $\operatorname{Se}(0.3)$ & $\operatorname{Se}(0.3)$ \\
\hline 19 & & & $\operatorname{Mi}(0.2)$ & $\mathrm{Mi}(0.2)$ & $\operatorname{Mi}(1.0)$ & $\operatorname{Mi}(0.2)$ & $\operatorname{Mi}(1.0)$ & $\mathrm{Mi}(1.0)$ & $\operatorname{Mi}(0.2)$ & $\operatorname{Mi}(1.0)$ & $\operatorname{Mi}(1.0)$ & $\operatorname{Mi}(0.2)$ \\
\hline 20 & & Mi $(0.9)$ & $\operatorname{Mi}(1.0)$ & Mi(1.0) & $\mathrm{Vs}(0.3)$ & $\operatorname{Mi}(1.0)$ & $\mathrm{Vs}(0.3)$ & $\mathrm{Se}(0.8)$ & & & & $\mathrm{Vs}(0.3)$ \\
\hline 21 & $\mathrm{Mi}(1.0)$ & - & - & - & - & -1 & $\operatorname{Mi}(1.0)$ & $\mathrm{Se}(0.8)$ & - & $\mathrm{Se}(0.4)$ & $\mathrm{Se}(0.8)$ & $\mathrm{Se}(0.4)$ \\
\hline 22 & - & $\operatorname{Se}(1.0)$ & $\mathrm{Mo}(0.8)$ & $\mathrm{Se}(0.9)$ & $\operatorname{Vs}(0.3)$ & $\mathrm{Se}(0.9)$ & $\mathrm{Mo}(1.0)$ & $\mathrm{Se}(1.0)$ & $\operatorname{Vs}(0.3)$ & $\mathrm{Se}(0.9)$ & $\mathrm{Se}(0.7)$ & $\operatorname{Vs}(0.3)$ \\
\hline
\end{tabular}

Fig.5. Few of the Represented Fuzzy Rules

The Rule base contains fuzzy rules that are in if....then forms. The if parts are called the antecedents while the then parts are called consequents. That is:

The database contains definitions of the membership functions.

From the Rule base, Rule 1 is interpreted as follows:

Rule 1: If a patient has a mild Body Temperature with degree of membership 0.1 and mild Chills with degree of membership 0.1 and mild Fatigue with degree of membership 0.1 and mild Fever with 0.1 and mild Headache with 0.1 and mild Diarrhea with 0.1 and mild Malaise with 0.1 and mild Muscular pain with 0.1 and mild Nausea with 0.1 and mild sweating with 0.3 and mild Vomiting with degree of membership 0.1 then The Malaria is of Mild Severity and of 0.1 degree of membership with the mild fuzzy set.

Fuzzy inference is the process of mapping from a given input to an output using fuzzy logic or the process of obtaining new knowledge from existing knowledge. In this study, the fundamental of reasoning is the generalized modus ponens that accommodates an inference when facts are partly known or when the facts are similar but not equal to the antecedents. This type of modus ponens is quite different from that used in standard logical propositional calculus for in standard logical prepositional calculus, inference will only take place if and only if the facts are exactly the same as the antecedents. The Generalized Modus Ponens is described as:
If (Antecedents) then (Consequent)

Antecedent: $\mathrm{x}$ is $\mathrm{D}$

Consequent: $\mathrm{y}$ is $\mathrm{E}$

Fuzzy Knowledge inferencing is a process that has some stages involved in it. These stages according to [16] are:

- The determination of the degree of match between the fuzzy input value and the defined fuzzy sets for each system input scalar variable.

- The calculation of the fire strength (degree of satisfaction) for each fuzzy rule based on the degree of match and the connectives (e.g. AND, OR) used with input variables in the antecedent part of the fuzzy rule. "AND” fuzzy set operator has been used in this study.

- The derivation of the control outputs based on the calculated fire strength and the defined fuzzy sets for each output variable in the consequent part of each fuzzy rule.

There are various methods for drawing inference in fuzzy systems: Max Min- that tests the magnitudes of all applicable rules and selects the highest one while the horizontal coordinate of the fuzzy centroid of the area under the function is taken as the output; Max Productthat scales each member function involved to fit under its respective peak value and the horizontal coordinate of the fuzzy centroid of the composite area under the functions is taken as the output; Averaging- clips each function at the average and the fuzzy centroid of the composite area is processed to become the output; and Root Sum Square 
Method. The last of the mentioned methods seems computationally complex but it is seen as the most suitable method for drawing inference and will be used as well in this study because of its advantages over the previously mentioned ones. It combines the effects of all applicable rules and scales the membership functions at their respective magnitudes. The output is obtained by computing the fuzzy centroid of the composite area.

Table 1. Abbreviated Words in Rule Base and Their Meanings

\begin{tabular}{|c|c|}
\hline Word & Meaning \\
\hline Fe & Fever \\
\hline Sw & Sweating \\
\hline Ch & Chills \\
\hline $\mathrm{Ha}$ & Headache \\
\hline $\mathrm{Ma}$ & Malaise \\
\hline $\mathrm{Fa}$ & Fodigue \\
\hline $\mathrm{BT}$ & Nemperature \\
\hline $\mathrm{Na}$ & Muscular Pain \\
\hline $\mathrm{Mp}$ & Vomiting \\
\hline $\mathrm{Vo}$ & Diarrhea \\
\hline $\mathrm{Di}$ & Moderate \\
\hline $\mathrm{Mo}$ & Mild \\
\hline $\mathrm{Mi}$ & Severe \\
\hline $\mathrm{Se}$ & Very Severe \\
\hline $\mathrm{Vs}$ & \\
\hline &
\end{tabular}

The Root Sum Square method has a formula mathematically denoted as follows:

$$
\sqrt{\sum R^{2}}=\sqrt{\left(R_{1}^{2}+R_{2}^{2}+R_{a}^{2}+\ldots \ldots \omega m \ldots \ldots m+R_{n}^{2}\right)}
$$

' $R$ ' stands for the firing strength or satisfactory strength or truth value of each applicable rule.

\section{4) Defuzzifier}

The Defuzzifier is the component of the fuzzy system that transforms the fuzzy set that we have as the output of the inference engine to the crisp value. This component carries out an operation that can be seen as the opposite operation of the Fuzzifier discussed earlier. Here, there are fuzzifiers' analogous membership functions used for the defuzzification as well. There are different approaches used for the defuzzification process. The commonly used of these methods are: mean of maximum (MOM) or middle of maxima, smallest of maximum (SOM), largest of maximum, bisector of area and centroid of area (COA) or center of gravity (COG) or weighted average method.

Center of gravity method is the most prevalent and physical appealing of all the defuzzification methods. In this research, discrete function form of the center of gravity (COG) method of defuzzifying the results of the inference engine was used due to its advantages over others and which make it to be the most prevalent and physically appealing of all methods. The mathematical formula for this method is represented as:

That is, the center of gravity $\left(\mathrm{p}^{*}\right)$ for the Fuzzy Set G. Where " $\int$ " denotes mathematical integration and $\mathrm{G}, \mathrm{p}$, are all variables. This formula is for any continuous membership function while that of discrete function is represented as:

$$
\operatorname{CoG}_{(\mathrm{G})}\left(\mathrm{p}^{*}\right)=\frac{\sum_{i=1}^{\mathrm{n}} \mu_{G}\left(\mathrm{p}_{\mathrm{i}}\right) \mathrm{p}_{\mathrm{i}}}{\sum_{\mathrm{i}=1}^{\mathrm{M}} \mathrm{\mu}_{\mathrm{G}}\left(\mathrm{p}_{\mathrm{i}}\right)}
$$

Where, $\mu \mathrm{G}(\mathrm{pi})$ is the membership value in the membership function and pi is center of membership function.

\section{Development of MFES}

MFES has employed the use of Java 2 Micro Edition (J2ME) in the development of its front end while the back end used Record Management System (RMS) that is also integrated into J2ME for developing the rule base and the database of membership functions. Netbeans 7.0.1 was used as the Integrated Development Environment that provided the available tools in designing, coding and testing MFES. The chosen Connection Limited Device Configuration (CLDC) and Mobile Information Device Profile (MIDP) for the MIDlet (MFES: J2ME Application) are 1.0 and 2.0 versions respectively. These chosen MIDP and CLDC have been considered so as to make the application accessible over many cell phones (because, few users use the latest phones that support the software platforms).

The inputs to the developed system are in the form of "Type of Symptom severity--day old of the symptom". The available symptom severities are Mild, Moderate, Severe and Very severe while the day ranges from 1 to 45 . The output from the system is a diagnostic result that tells a user the Severity of Malaria suffered from.

ClamshellCldcPhone1 Emulator was used in simulating the normal execution of the MFES and finally, Nokia X2 was used in the implementation of MFES for various instances of the scalar inputs.

\section{RESUlTS AND DisCUSSION}

A. Results

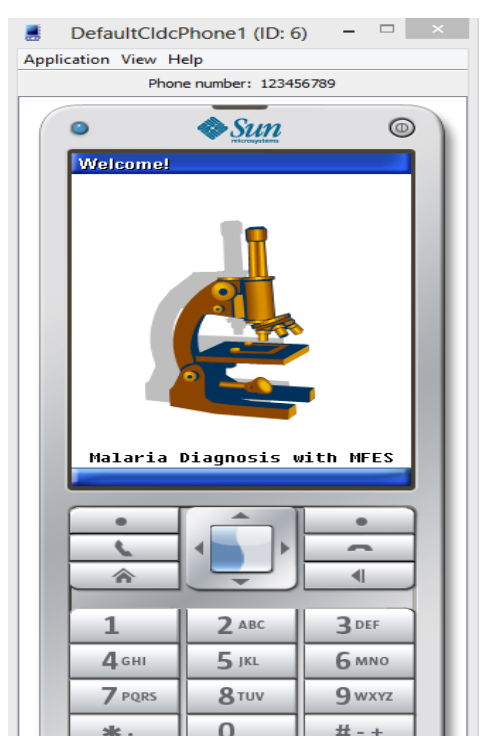

Fig.6. The Splash Screen 


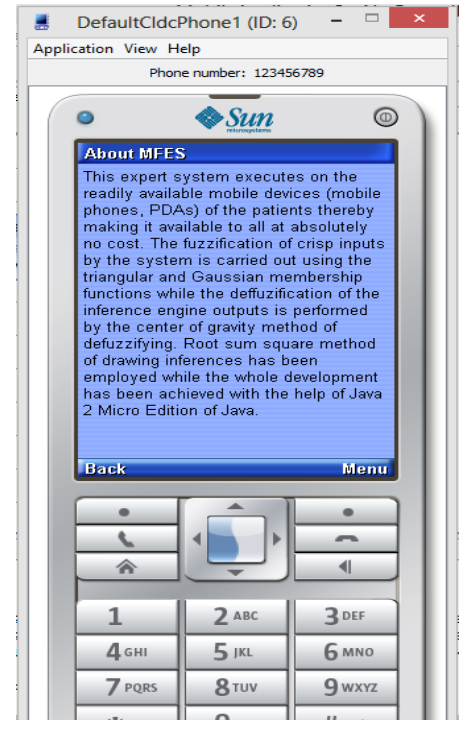

Fig.7. The Help Page

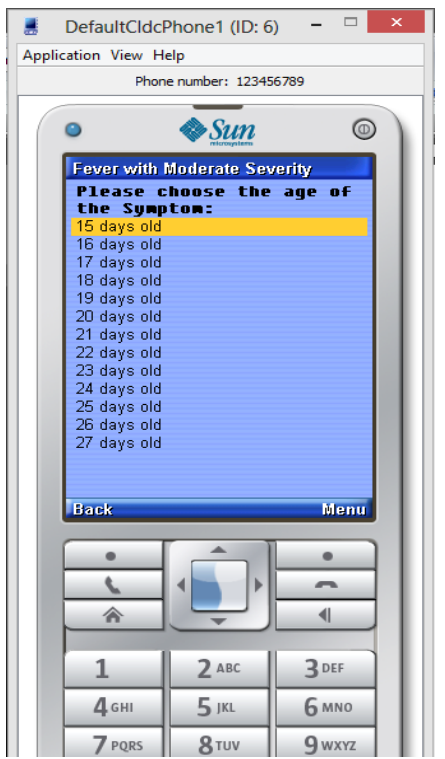

Fig.8. Fever Page showing Symptom's Age

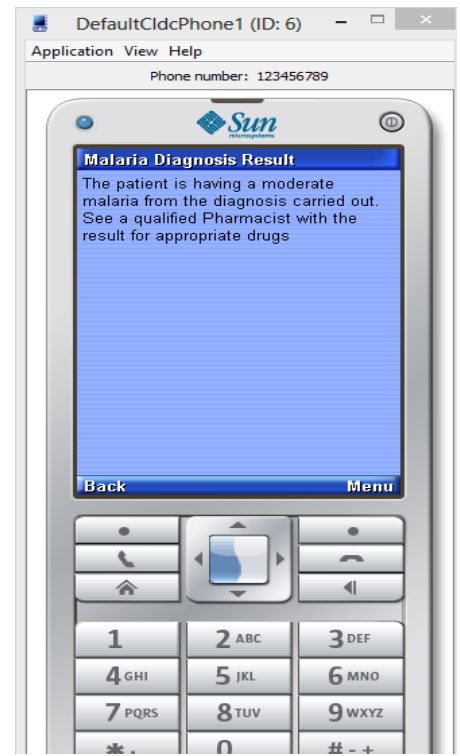

Fig.9. Result of a Diagnosis

\section{B. Discussion of Results}

The Interfaces shown in the preceding sub section are the results of MFES when tested with collected symptoms from few different users. The diagnostic messages provided by the system were achieved after the execution of the Fuzzification, Inference and defuzzification sub tasks.

For Example:

A patient that observed malaria symptoms shown in table 2 was considered and after the fuzzification of the scalar inputs, the results of the fuzzification process are shown in table 3 .

Table 2. Symptoms for the Diagnosed Patient

\begin{tabular}{|c|c|c|}
\hline Symptom (input 1) & Severity (input 2) & $\begin{array}{c}\text { Age of Symptom } \\
\text { in days (input 3) }\end{array}$ \\
\hline Body temperature & Severe & 23 \\
\hline Chills & Severe & 23 \\
\hline Fatigue & Moderate & 22 \\
\hline Headache & Moderate & 19 \\
\hline Fever & Moderate & 22 \\
\hline Diarrhea & Severe & 24 \\
\hline Malaise & Moderate & 25 \\
\hline Muscular pain & Severe & 24 \\
\hline Nausea & Severe & 24 \\
\hline Sweating & Severe & 18 \\
\hline Vomiting & Moderate & 25 \\
\hline
\end{tabular}

\section{1) Rule Base Evaluation for the Patient}

The fuzzified values from the patient when compared with the antecedents that are contained in the rule base have caused thirteen (13) rules (rule 3, 6, 7, 10, 13, 14, 15, $16,17,18,20,21$ and 22) to be fired.

Therefore, inference was inferred using the Root Sum Square method of inference as illustrated shortly:

Table 3. Symptoms for the Diagnosed Patient

\begin{tabular}{|c|c|}
\hline Symptoms & Fuzzy value \\
\hline Body temperature & Severe $(0.3)$ \\
\hline Chills & Severe $(0.3)$ \\
\hline Fatigue & Moderate $(0.9)$ \\
\hline Headache & Moderate $(0.9)$ \\
\hline Diarrhea & Severe $(0.4)$ \\
\hline Malaise & Moderate $(0.4)$ \\
\hline Muscular pain & Severe $(0.6)$ \\
\hline Nausea & Severe $(0.4)$ \\
\hline Sweating & Severe $(0.4)$ \\
\hline Vomiting & Moderate $(0.6)$ \\
\hline$\sqrt{\sum_{\text {Moderate }}^{2}=\sqrt{R_{3}^{2}+R_{6}^{2}+R_{7}^{2}}}=$ \\
$\sqrt{(0.3)^{2}+(0.3)^{2}+(0.3)^{2}}=\sqrt{0.27} \approx 0.52$ \\
\hline
\end{tabular}




$$
\begin{gathered}
\sqrt{\sum R_{\text {Severe }}^{2}}=\sqrt{R_{13}^{2}+R_{15}^{2}+R_{16}^{2}+R_{18}^{2}+R_{21}^{2}} \\
=\sqrt{(0.3)^{2}+(0.3)^{2}+(0.3)^{2}+(0.3)^{2}+(0.4)^{2}} \\
=\sqrt{0.52} \approx 0.72 \\
\sqrt{\sum R_{\text {Very Severe }}^{2}}= \\
=\sqrt{(0.3)^{2}+(0.3)^{2}+(0.3)^{2}+(0.3)^{2}+(0.3)^{2}} \\
=\sqrt{0.45} \approx 0.67
\end{gathered}
$$

\section{2) Defuzzification of Inference Output}

Using the center of gravity (COG) method of inference, the crisp output is computed as follows:

$$
\text { Output }=\frac{(0.0 * 14)+(0.52 * 21)+(0.72 * 28)+(0.67 * 40)}{(0+0.52+0.72+0.67)}=30.30 \%
$$

The interpretation of the output means that the patient has moderate malaria as illustrated in Fig. 3.

\section{CONCLUSION}

This study has attempted the development of a mobile based fuzzy system that diagnoses malaria with uncertainties as expected of a human expert in the field of medicine. It has really brought the medical exercise of malaria diagnosis to the door step of every needy patient who might have been shortchanged by the problem of insufficient doctors, which is the active reason for the prevalence of malaria in Africa and in other endemic areas. The fuzzy system being a mobile base application (MIDLet) that does not require any internet connection and PCs but, the available MIDP 2.0 - CLDC1.0 supported cell phones that are possessed by an average patient in the affected areas. This costless feature of MFES has made it to achieve the goal of general accessibility and usability.

MFES can also serve as a decision support system for young medical practitioners who may want to acquire more knowledge on the diagnosis of malaria if rationally handled. A partial or full implementation of the developed mobile fussy system will assist in providing effective malaria diagnosis in the endemic regions where medical practitioners are limited in number due to some reasons and it will also assist in reducing the workloads of medical personnel who work under duress.

\section{ACKNOWLEDGMENT}

We want to use this opportunity to acknowledge the sources of the knowledge represented in this MFES. More so, acknowledgment of Mr. J. O. Owoseni of the Department of Applied Geology, Federal University of Technology, Akure, Nigeria will never be toyed with because of his academic guidance. The Family of Mr. \&
Mrs. S. B. Owoseni is recognized at this point as well for her assistance in all forms. To the management and staff of Interlink Polytechnic, Ijebu Jesa, Osun State, Nigeria, we say a big thank you.

\section{REFERENCES}

[1] United State Department of Health and Human Services, "Understanding Malaria: Fighting an Ancient Scourge (NIH Publication No. 07-7139) 2007”, National Institutes of Health, retrieved on 22/05/2015, from http://www.niaid.nih.gov/topics/malaria/documents/malari a.pdf.

[2] S. Tunmibi, O. Adeniji, A. Aregbesola, and A. Dasylva, "A Rule Based Expert System for Diagnosis of Fever", International Journal of Advanced Research, 2013, 1(7), pp. 343-348.

[3] A. O. Adetunmbi, A. Oguntimilehin, and S.O. Falaki, "Web-Based Medical Assistant System for Malaria Diagnosis and Therapy", GESJ: Computer Science and Telecommunications, 2012, 1(33), pp. 42-53.

[4] World Health Organization, "Guidelines for the treatment of malaria", 2nd Edition, retrieved on 06/01/2011, from http://whqlibdoc.who.int/ publications/2010.

[5] F. M. E. Uzoka, O. U. Obot and K. Barker, "A performance comparison of Fuzzy Logic and AHP as engines for the development of Intelligent Medical Diagnosis Systems" Nigeria Computer Society 23rd National Conference, 2009, pp. 135- 150.

[6] I. Kamukama, "Clinical protocol-based decision support system for malaria treatment", M.Sc. Computer Science Thesis, Makerere University, 2009, retrieved on 22/05/2015, from http://hdl.handle.net/10570/463 /123456789/628/3/kamukama-ismail-cit-mastersreport.pdf.

[7] A. B. Adehor, and P. R. Burrell, "The Integrated management of health care strategies and differential diagnosis by expert system technology: A singledimensional approach", World Academy of Science, Engineering and Technology, 2008, 44, pp. 533-538.

[8] S. O. Anigbogu, "Artificial intelligence-based medical diagnostic expert system for malaria and the related ailments", International Journal of Computer Science \& Applications, 2006, 12(1), retrieved on 06/12/2013, from http://www.researchgate.net/publication/240702829_Artif icial_Intelligence-Based_Medical_Diagnostic_Expert_ System_For_Malaria_And_The_Related_Ailments.

[9] M. E. Rafael, T. Rerrie, A. Magill, Y. Lim, F. Girosi, and R. Allan, "Reducing the burden of childhood malaria in Africa: the role of improved diagnostics", Nature Publishing Group, pp. 39-48, retrieved on 06/12/2013 from http://www.nature.com/nature/journal/v444/n1s/full /nature05445.html

[10] World Health Organization, "Guidelines for the treatment of malaria", Second Edition, retrieved on 22/05/2015, from

http://whqlibdoc.who.int/1207966204/9789241547925_en g.pdf.

[11] D. Chandramohan, I. Carneiro, A. Kavishwar, R. Brugha, V. Desai, and B. A. Greenwood, "Clinical algorithm for the diagnosis of malaria: results of an evaluation in an area of low endemicity", Tropical Medicine and International Health, 2001, 6(7), pp. 505-510.

[12] K. A. Bojang, S. Obaro, L. A. Morison, and B. M. Greenwood, "A prospective evaluation of a clinical algorithm for diagnosis of malaria in Gambian Children", Tropical Medicine and International Health, 5(4), pp. 231-236. 
[13] M. Patel, and P. Virparia, "Designing Mobile Based Fuzzy Expert System Framework for Viral Infection Diagnosis", International Journal of Current Research and Review, 2012, 4 (12), pp. 139-146.

[14] M. O. A. Olufemi, "Mobile Phone-Based Expert System for Disease Diagnosis", retrieved on 22/05/2015, from http://www.irma-international.org/412224158/A-MobilePhone-Based-Expert-System-for-Disease-Diagnosis.pdf.

[15] M. Scarpiniti, "Neural Networks Lesson 9- Fuzzy Logic", 2009, retrieved on 22/05/2015, from http://ispac.ing.uniroma1.it/scarpiniti/files/NNs/Less9.pdf

[16] P. P. Costas and I. S. Constantinos, "Chapter 15: Fuzzy Reasoning", retrieved on 22/05/2015, from http://www.inf.ufpr.br/1420547959/FR.pdf.

\section{Authors' Profiles}

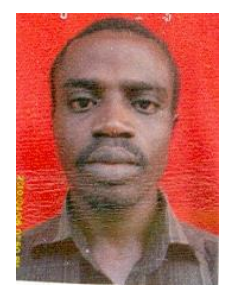

Alaba T. Owoseni was born on April14, 1984, as a Nigerian in the south-west part of the country. He had bachelor of technology in computer engineering from Ladoke Akintola University of Technology, Ogbomoso, Nigeria in 2009 with master of technology in computer science from Federal University of Technology Akure, Nigeria in 2015. Currently, he is preparing to commence his doctor of philosophy in computer science.
$\mathrm{He}$ is currently a LECTURER II in the department of computer science, Interlink Polytechnic, Ijebu Jesa, Nigeria and his areas of interest include fuzzy systems, soft computing, information retrieval, software engineering and programming theory.

Mr. Owoseni is a member of international association of engineers and a member of few of its societies. He is also a member of international association for computer science and information technology.

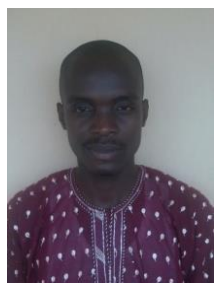

Isaac O. Ogundahunsi was born in Ilesa of Osun State, Nigeria in 1979. He had his ND and HND in Computer Science from Osun State College of Technology, Esa Oke and Osun State Polytechnic, Iree. He also had Postgraduate Diploma in Computer Science (PGDCS) from Federal University of Technology, Akure. He had his Bachelor of Science (Bsc) in Computer Science from Joseph Ayo Babalola University, Ikeji Arakeji. He is currently preparing for his masters degree in computer science.

$\mathrm{He}$ is currently a lecturer in the department of Computer Science, Interlink Polytechnic, Ijebu Jesa. His research interests.

How to cite this paper: Alaba T. Owoseni, Isaac O. Ogundahunsi,"Mobile-Based Fuzzy Expert System for Diagnosing Malaria (MFES)", International Journal of Information Engineering and Electronic Business(IJIEEB), Vol.8, No.2, pp.14-22, 2016. DOI: 10.5815/ijieeb.2016.02.02 